\title{
An Attractive Relation of Human Herpesvirus-8 with Multicentric Castleman's Disease
}

\author{
Key words: IPL, KSHV, IL-6
}

Hayashi et al reported a case of Multicentric Castleman's disease (MCD) with human herpesvirus-8 (HHV-8) infection in this issue (1).

See also p 279.

This is the first report of the association between MCD and HHV-8 in Japan. MCD is known in Japan as idiopathic plasmacytic lymphoadenopathy (IPL) with polyclonal hyperimmunoglobulinemia. Interleukin-6 (IL-6) has been thought to play an important role in the pathogenesis of MCD because of the high level of IL-6 in the sera of patients with MCD. Follicular hyperplasia with proliferation of plasma cells in the lymph node is characteristic of the histopathological findings of MCD. The "onion skin appearance", one of the histological features found in hyaline-vascular type of Castleman's disease, reminds some pathologists of Kaposi's sarcoma (KS). In 1996, an attractive association was proposed. Soulier et al reported the detection of a DNA fragment of HHV-8 in MCD tissues by polymerase chain reaction (PCR) analysis (2).

HHV-8 (human herpesvirus-8 or Kaposi's sarcoma-associated herpesvirus: KSHV) is a new member of human herpesviruses, and was identified from acquired immunodficiency syndrome (AIDS)-associated KS in 1994 (3). This virus is considered as an oncovirus for the following reasons: 1) HHV-8 is detected in malignancies such as $\mathrm{KS}$ and primary effusion lymphoma (PEL) (4), 2) HHV-8 has nucleotide sequence homology to Epstein-Barr virus (EBV) and herpesvirus saimiri (5), which are known to cause lymphomas, and 3) HHV-8 encodes some human gene homologues, such as bcl-2, cyclin-D1 and G-protein-coupled receptor (5). In fact, HHV-8 has been detected in over $90 \%$ of AIDS-KS tissues by PCR and some ORFs encoded in HHV-8 have been shown to have transformation activities (6-8).

In order to determine the association of MCD with HHV-8, we must clarify at least three questions. The first question is whether HHV-8-encoded IL-6 (viral IL-6: vIL-6) plays a role in the proliferation of plasma cells. HHV-8 encoded a gene homologue of human IL-6 (hIL-6), which makes this association attractive in the pathogenesis of MCD. The level of IL-6 is high in the sera of patients with MCD as well as KS. In addition, vIL-6 was shown to be functional in the B9 cell proliferation assay (9). However, the amount of vIL-6 in sera of patient with MCD has not been determined yet. The other prob- lem about IL-6 is whether vIL- 6 can induce plasma cells to produce hIL-6. Autocrine activation of vIL-6 and hIL-6 is expected; such activation has been demonstrated not only in vivo, but also in vitro.

The second question is that the localization of HHV-8 in MCD has not been clarified yet. Although the expression of vIL-6 has been demonstrated in the lymph node of MCD using a monospecific rabbit antibody specific to vIL-6 (10). vIL-6 is expressed in a small portion of stromal cells of the interfollicular area in the lymph nodes with MCD. Previous studies employed in situ hybridization and immunohistochemistry detecting only lytic proteins/mRNA or viral particles, although latent proteins may play important roles in the pathogenesis of lymphocryptovirus such as EBV. HHV-8 encodes some latent proteins/genes such as latency-associated nuclear antigen (LANA), however, it is not easy to detect these latent proteins/ genes by immunohistochemistry or in situ hybridization.

The third question is in the serological studies. Anti-HHV-8 antibodies are detected in the sera from HHV-8 infected individuals. However, to date there is little serological information indicating the association between MCD and HHV-8 infection.

Thus, HHV-8 is an attractive agent for the pathogenesis of MCD, especially in the function of IL-6. Further studies will clarify the role of HHV-8 in the pathogenesis of MCD.

\section{Harukata KATANO, DDS and Tetsutaro SATA, MD Laboratory of Pathology, AIDS Research Center, National Institute of Infectious Diseases, 1-23-1, Toyama, Shinjuku-ku, Tokyo 162-8640}

\section{References}

1) Hayashi M, Aoshiba K, Shimada M, Izawa Y, Yasui S, Nagai A. Kaposi's sarcoma-associated herpesvirus infection in the lung in multicentric Castleman's disease. Intern Med 38: 279-282, 1999.

2) Soulier J, Grollet L, Oksenhendler E, et al. Kaposi's sarcoma-associated herpesvirus-like DNA sequences in multicentric Castleman's disease. Blood 86: 1276-1280, 1995.

3) Chang Y, Cesarman E, Pessin MS, et al. Identification of herpesvirus-like DNA sequences in AIDS-associated Kaposi's sarcoma. Science 266: 18651869, 1994.

4) Nador RG, Cesarman E, Chadburn A, et al. Primary effusion lymphoma: a distinct clinicopathologic entity associated with the Kaposi's sarcomaassociated herpes virus. Blood 88: 645-656, 1996.

5) Russo JJ, Bohenzky RA, Chien MC, et al. Nucleotide sequence of the Kaposi sarcoma-associated herpesvirus (HHV8). Proc Natl Acad Sci USA 93: 14862-14867, 1996.

6) Bais C, Santomasso B, Coso O, et al. G-protein-coupled receptor of 
Kaposi's sarcoma-associated herpesvirus is a viral oncogene and angiogenesis activator. Nature 391: 86-89, 1998 (Published erratum appears in Nature 392: 210, 1998).

7) Lee H, Veazey R, Williams K, et al. Deregulation of cell growth by the $\mathrm{K} 1$ gene of Kaposi's sarcoma-associated herpesvirus. Nat Med 4: 435440, 1998.

8) Sarid R, Sato T, Bohenzky RA, Russo JJ, Chang Y. Kaposi's sarcomaassociated herpesvirus encodes a functional bcl-2 homologue. Nat Med
3: 293-298, 1997.

9) Moore PS, Boshoff C, Weiss RA, Chang Y. Molecular mimicry of human cytokine and cytokine response pathway genes by KSHV. Science 274: 1739-1744, 1996.

10) Parravinci $C$, Corbellino M, Paulli M, et al. Expression of a virus-derived cytokine, KSHV vIL-6, in HIV-seronegative Castleman's disease. Am J Pathol 151: 1517-1522, 1997. 